\title{
Islamic Republic of Afghanistan: Interim Poverty Reduction Strategy Paper- Joint Staff Advisory Note
}

The attached Joint Staff Advisory Note (JSAN) on the Interim Poverty Reduction Strategy Paper for the Islamic Republic of Afghanistan, prepared jointly by the staffs of the World Bank and the IMF, was distributed with the member country's Interim Poverty Reduction Strategy Paper (PRSP) to the Executive Boards of the two institutions. The objective of the JSAN is to provide focused, frank, and constructive feedback to the country on progress in implementing its Poverty Reduction Strategy (PRS).

To assist the IMF in evaluating the publication policy, reader comments are invited and may be sent by e-mail to publicationpolicy@imf.org.

Copies of this report are available to the public from

International Monetary Fund • Publication Services

$70019^{\text {th }}$ Street, N.W. • Washington, D.C. 20431

Telephone: (202) 623-7430 • Telefax: (202) 623-7201

E-mail: publications@imf.org•Internet: http://www.imf.org

\section{International Monetary Fund Washington, D.C.}





\title{
INTERNATIONAL MONETARY FUND AND \\ INTERNATIONAL DEVELOPMENT ASSOCIATION
}

\author{
ISLAMIC REPUBLIC OF AFGHANISTAN
}

\author{
Joint Staff Advisory Note on the Interim Poverty Reduction Strategy Paper \\ Prepared by the Staffs of the International Monetary Fund \\ and the International Development Association \\ Approved by Juan Carlos Di Tata and Matthew Fisher (IMF) \\ and Praful Patel (IDA)
}

May 15, 2006

\section{OVERVIEW}

1. On January 22, 2006, President Hamid Karzai and his cabinet formally approved the Interim Afghanistan National Development Strategy (I-ANDS)"A Strategy for Security, Governance, Economic Growth, and Poverty Reduction." This five-year strategy follows the National Development Framework prepared in 2002 and the Securing Afghanistan Future (SAF) exercise prepared in 2004. The I-ANDS was presented and discussed at an International Donors' Conference on Afghanistan, in London, on January 31 and February 1, 2006.

2. The I-ANDS is complemented by the Afghanistan Compact between Afghanistan and its international partners. The Compact—which follows the 2001 Bonn Agreement and was also discussed in London and subsequently endorsed by the UN Security Councilsets out detailed outcomes, benchmarks, and timelines in the areas of security, governance, rule of law, human rights, and economic and social development. As part of the Compact, the government and the international community have also committed jointly to improving the effectiveness and accountability of international assistance in line with the targets of the Paris Declaration.

3. Four years into Afghanistan's reconstruction process, many challenges to building institutions, sustaining growth, strengthening capacity, and reducing poverty remain. Therefore, a coherent and well coordinated national strategy is very much welcome. Not only does the I-ANDS constitute a comprehensive plan for developing the ANDS, but it also provides a cohesive broad policy framework to increase growth and reduce poverty. Nevertheless, challenges remain to be addressed in the initial stages of the implementation of the I-ANDS and in the transition to the ANDS. To attain both overarching and sectoral objectives, it is vital to improve the costing and prioritization of near-term policies in key sectors and proposed anti-poverty programs, within sustainable medium-term budget and fiscal frameworks. Furthermore, there is an urgent need to address the major capacity constraints that impede effective implementation and monitoring of the strategy. 
4. The I-ANDS has been submitted to the IMF and World Bank Executive Boards of Directors as Afghanistan's Interim Poverty Reduction Strategy Paper (I-PRSP). This Joint Staff Advisory Note (JSAN) provides staffs' advice on key priorities to strengthen the strategy as the I-ANDS is implemented and the ANDS is prepared, while pointing out at some weaknesses that could undermine successful implementation of the strategy.

\section{Consultation Process}

5. In terms of process, the preparation of the I-ANDS included a significant consultative process, as early consultation was perceived to be a precondition for acceptance later. Building on earlier development frameworks, the I-ANDS process was launched by President Karzai at the 2005 Afghanistan Development Forum. In August 2005, the government formally established a Presidential Oversight Committee and Working Group to spearhead its development, which ensured ownership of the I-ANDS by the government. More than 400 consultative meetings with stakeholders were conducted (with sectoral ministries, provincial governors, the private sector, members of local communities, civil society organizations, a number of parliamentarians, donors, foreign office officials, and ambassadors). All meetings were public, with details and minutes (where available) posted on the ANDS website. As part of the institutional framework set up by the authorities to conduct the I-PRSP process, an External Advisory Group (EAG) was established as a forum for donors to provide feedback and closely interact with the Working Group at all stages of the process.

6. The I-ANDS rightly recognizes the importance of the consultation process toward a complete ANDS and outlines the proposed participatory process, including how to deepen and broaden discussion and analytical work through Consultative Groups (CGs) and other formal and informal structures. Because Afghanistan remains a divided society, deep and meaningful consultation is essential for broad-based ownership. The structure of CGs will be used as a forum for ongoing consultations on the full ANDS, and participation will be extended to the newly elected Parliament, provincial councils, district leaders, communities, as well as civil society, expatriate Afghans, and the international community. Special consideration in the consultation process will also be given to engaging with national and international NGOs who have been working alongside Afghans, sometimes for decades. It will also be important to establish mechanisms that allow the government to consult with the poor, and this has not been documented clearly in the strategy. The government should take into account that this consultation process will be very demanding — and time consuming — as many unanswered issues require further analysis and research.

\section{Strengthening Links Between the PRS And Domestic Processes}

7. The I-ANDS rightly emphasizes the national budget as a central instrument of government policy. Commendably, government has adopted a Medium-Term Fiscal Framework (MTFF) as part of the I-ANDS. However, as the I-ANDS notes, the challenge of translating the interim strategy into annual budgets is enormous: the development strategy is 
very ambitious and remains to be costed and fully reconciled with the MTFF; domestic revenues remain limited and external assistance, although large, is somewhat unpredictable and largely outside the government framework; implementation capacity of the government remains limited; and tracking and monitoring systems are largely missing. Government should focus on developing the linkages between the I-ANDS/ANDS and annual budgets. Priorities in this regard include a strengthening of the MTFF toward more realistic budgets (starting in 2006), an identification of the main fiscal risks, the costing of the major programs proposed, and the adoption of clear and effective prioritization criteria.

8. As the interim strategy presents a very ambitious five-year framework, there is an urgent need for prioritization. Moving toward a full strategy requires balancing the need for short term, visible results in order to secure stability, with the longer-run development agenda. In order to avoid generating unrealistic expectations, the proposed prioritization framework needs to be strengthened and operationalized to reconcile a "needs-based" approach with a realistic "top-down" approach (allocation under resources constraints) and recognition of the capacity constraints that will continue to hinder development spending. Further prioritization would, in our view, focus clearly on capacity building, strengthening statistical and analytical capacity, and strongly linking the I-PRSP with the budget. This will provide better guidance to policy makers and help ensure a smooth transition to the full PRSP.

\section{Effective integration of the I-ANDS with national processes will require clear} institutional arrangements. There is considerable risk that the interim strategy may not be fully integrated into budget formulation and execution processes. In particular, the continued absence of basic monitoring capacities may lead to the duplication of certain basic functions, which may hamper capacity development, particularly in the Central Statistics Office (with regard to household surveys), the Ministry of Economy and central bank (macroeconomic reporting), and the Ministry of Finance (public finance monitoring and project tracking systems). Therefore, the government should seek to institutionalize processes so that policy formulation and monitoring mechanisms flow into government decision-making and annual budget preparation processes. Close coordination of monitoring arrangements for the Afghanistan Compact would also be advisable.

10. The I-ANDS emphasizes the continuing need to improve the alignment of donor and government priorities, by channeling more funds directly through the Core Budget. Currently, domestic revenues account for less than 10 percent of total budgetary expenditures and over 75 percent of external assistance resources are channeled outside of the government's financial management systems. This weakens formal government appropriation procedures, negatively affects project prioritization and expenditure tracking systems, and blurs accountability relationships. We support the consolidation of fiscal operations while recognizing that absorbing additional responsibilities into the Core Budget, if not accompanied by more funding, would reduce the available fiscal space, particularly over the medium term. In this context, we encourage the authorities to work closely with the donor community to strengthen government's capacity to implement its program. This would 
bolster the government's policy toward better aid effectiveness and contribute to developing its capacity to meaningfully absorb these flows. Also, improvement in government systems and tightening of fiduciary standards are critical to ensure successful implementation of this agenda.

\section{Strengthening The PRS ANd EnhanCing IMPlEMENTATiON}

\section{A. Poverty Diagnostic}

11. The I-ANDS builds on existing data to present a poverty profile and propose policies. With GDP per capita (excluding opium income) at US\$293 in 2005/06 and the fall-out of more than a quarter-century of conflict, poverty in Afghanistan is pervasive. Social indicators are very weak, with life expectancy at 46 years, an 80 percent illiteracy rate, and infant mortality at 140 per 1,000 live births. Disparities are considerable, between men and women as well as between urban and remote rural areas.

12. Nonetheless, there are severe limitations in the coverage and quality of poverty data in Afghanistan and the ANDS represents an opportunity to address these weaknesses. A preliminary diagnostic on rural poverty highlights the role of agriculture, droughts, and migration. Future analysis should consider broader dimensions of poverty (instead of the current over-reliance on food poverty and food and energy insecurity), including its income and consumption dimensions, and gradually disaggregate poverty data by province and district, as well as by demographic groups, including gender. The government should consider building on the recent completion of the 2005 National Risk and Vulnerability Assessment survey (NRVA) to deepen the poverty diagnostic, develop capacity to analyze data, establish a baseline against which progress in poverty reduction can be measured, and, based on this experience, design the next generation of surveys and diagnostics.

\section{The I-ANDS is correctly anchored in enhancing growth and targeting the} MDGs. However, the choice and prioritization of investments and programs need to be better related to the overarching growth and poverty reduction goals. In preparing the full ANDS, existing programs will need to be evaluated and prioritized. In particular, the establishment of a social protection program provides an opportunity to address the needs of the most vulnerable. The government could review the realism of the benchmarks set in this area and clearly define a monitoring and evaluation framework to assess progress toward these benchmarks. It is vital that donors work closely with the government to limit the disconnect between needs and actual capacities to design targeted programs.

\section{B. Targets, Indicators, and Monitoring}

\section{The I-ANDS defines a number of medium- and long-term goals for poverty} reduction outcomes and establishes indicators of progress and medium-term targets. While supporting such a framework, we note three weaknesses. First, there is little capacity to monitor a number of these indicators. Second, the targets are rather numerous, so prioritization would be essential given limited implementation and monitoring capacity. In 
some cases, indicators (e.g., rural infrastructure, disaggregated by province and district) are not available, making targets meaningless. Moreover, baseline data for key indicators for monitoring outcomes (including MDG indicators) are still evolving given the data limitations. Third, in some cases, the targets may be unrealistic or overly ambitious (such as some education targets). Realism needs to be factored in, as several programs have not been designed, funding has not been secured, and implementation will take time.

\section{Strengthening government capacity to monitor poverty outcomes, as well as} developing expenditure tracking systems, should be one of the priorities for the period of the interim strategy. Given lack of progress in recent years in developing outcome-oriented monitoring systems (with the exception of certain health and education statistics), the government needs to focus immediately on implementing the core elements of the Statistical Master Plan (SMP). Ongoing surveys provide a foundation for learning and designing next steps in building statistical capacity. The elaborate institutional structure proposed by the I-ANDS will have to be reviewed after initial experimentation to ensure effectiveness.

\section{Macroeconomic Framework, Fiscal Choices, and Financing Plan}

\section{The overall macroeconomic framework appears reasonably sound and} illustrates the government's commitment to establishing conditions for lasting growth. Robust economic growth since 2002/03 has doubtless been an important factor in maintaining a relatively stable political and economic environment. The I-ANDS objective of maintaining economic growth in the order of 10 percent per annum is certainly a necessary condition to enhance political stability and reduce poverty while eliminating opium activity over time. Developing the ANDS requires consistent macroeconomic frameworks, anchored on a more comprehensive analysis. The commitment to gradually reduce inflation is essential to ensuring a real improvement in living standards. Moreover, while maintaining the current macroeconomic stance and strengthening macroeconomic management to adapt to a changing environment (e.g., adjust monetary policy to reflect the development of a banking sector) and strengthen external competitiveness, the government needs to deepen its analysis of the long-term drivers of growth.

\section{The challenges to the macroeconomic framework are numerous, including:}

(i) enhancing national security and stability outside of Kabul by strengthening the police and judicial systems; (ii) disarming illegally armed groups; (iii) deepening the political normalization process; (iv) phasing out the opium economy, which alone constituted around 37 percent of official GDP in 2005/06; (v) protecting the vulnerable segments of the population against supply shocks stemming from lingering drought and other natural disasters; and (vi) managing effectively the significant inflows of external aid. Addressing these challenges will require complementary and well sequenced economic reforms and careful economic management.

18. The fiscal directions indicated by the MTFF and the continuing commitment to fiscal discipline are positive features of the I-ANDS. On the revenue side, Afghanistan has one of the lowest revenue to GDP ratio in the world (around 5 percent) and there is a need to 
implement forcefully the government's plan to enhance revenue mobilization. On the expenditure side, fiscal sustainability considerations embodied in the MTFF should be a central tool of government decision making, especially with regard to pay reform and determining staffing size (particularly in the security, education, and health sectors). While more realism is also needed about the pace of development spending, in order to improve the credibility of the budget, consideration also needs to be given to smoothing the path of expenditures, given the high exposure to volatile aid flows. Finally, as committed in the Paris Declaration on aid effectiveness and reiterated in the Compact, donors are encouraged to improve the predictability and reduce the volatility of aid so that government can plan for and manage effectively public resources. Government and donors could consider making increased predictability and reduced aid volatility explicit targets of the ANDS.

\section{Governance, Public Sector Management, and Implementation Capacity}

\section{Institutional development and governance are the cornerstone of the I-ANDS.}

Progress in these areas is critical to: (i) strengthen the administration's credibility and build accountability to the Afghan people; (ii) combat corruption; and (iii) create capacity to deliver the ambitious agenda set out in the I-ANDS. However, the ANDS should recognize that building institutions is a long-term endeavor, requiring careful prioritization and sequencing. Limited progress in these areas, in spite of considerable efforts and investments since early 2002, suggests the need for a concerted, well designed, and realistic approach.

\section{A first priority is to review the role of the government with respect to service} delivery as envisaged by the I-ANDS for 2006. We endorse the I-ANDS objectives of developing a lean and effective public sector and its commitment to private-sector led growth: this correctly takes into account limited capacity, need for prioritization, and experience from Afghanistan as well as other countries. While the I-ANDS contains encouraging statements, such as the continuation of the policy to contract out basic health services, generally, it does not delineate the specific role of the government in different sectors. These policies should be developed during the completion phase of the ANDS and beyond, in light of capacity constraints and the public's ability to hold government and other service providers accountable. Similarly, an evidence-based and participatory debate on the role of the central government, its decentralized offices, the municipalities, and community councils would open avenues for strengthening service delivery. In particular, the role of Community Development Councils (CDCs), which were created by the National Solidarity Program (NSP), remains to be defined and connected to other elements of the governance structure. On this basis, central ministries as well as provincial and district offices could be reformed to perform the functions assigned to them.

21. The second major constraint is the lack of qualified human resources. The I-ANDS puts forward a comprehensive public administration reform strategy, with adequate focus on pay reform, merit-based recruitment, and training. The government will need to confront those implementation factors critical to reaching the desired outcomes. First, in deciding what functions it will undertake, the government needs to take account of the scarcity of well-trained professionals and managers. Second, the government needs to adopt a clear pay strategy taking into account that (i) market rates for qualified personnel have 
increased substantially with the influx of external support and (ii) the government has limited resources with which to compete for personnel. In its effort to attract and retain higher qualified personal, the government faces substantial long-term fiscal risks, which could reduce the availability of nonsalary and nonrecurrent fiscal resources to support service delivery. While the I-ANDS correctly challenges the cost-effectiveness of external assistance received so far, the government should develop strategies to effectively use well targeted external support and technical assistance. Addressing human resource constraints will require extensive coordination with the international community.

22. The I-ANDS appropriately emphasizes the need to combat corruption, a key element of the governance agenda. Indeed, anecdotal information points to high levels of corruption (state capture, petty corruption, and bribery) across many state institutions, undermining government's support from its people, its effectiveness, and its efforts to increase budget support from donors. The proposed anti-corruption strategy takes a holistic approach, covering public sector management, public accountability systems, the legal framework and the judicial system, corruption within counternarcotics institutions, and monitoring. We support this holistic approach and suggest the full ANDS pays particular attention to transparency, not only in areas like human resources, public expenditure, procurement, and revenue collection, but also in privatization and the management of mineral and petroleum resources.

\section{E. Sectoral Policies}

23. Overall, the proposed priority areas for public investment (infrastructure development, institutional and human capacity development, poverty and social protection, and creating an enabling environment for the private sector supported by enhanced security and governance) appear consistent with the growth and poverty reduction objectives. As noted above, these areas need further prioritization based on additional analytical reviews, costing, and identification of implementation constraints. The government's approach to tightly link security, institution building, governance, and development (including through the adoption of a pillar of the I-ANDS for security and of a ninth MDG for security), is welcome. Security issues, however, have not been reviewed extensively for the purposes of this JSAN.

\section{Proposed investments in agriculture and rural development show a strong} commitment to rural areas, and to supporting the private sector. We concur with the view that developing the rural economy is critical for the success of the overall strategy as government seeks to reduce opium production. However, in many areas, specific policies and institutional reforms need to be determined to transform the public sector into an enabler of the private sector. Rural infrastructure will deliver benefits only if coordination between the various stakeholders - public and private - is improved. Moreover, laws need to be developed to support the development of the rural economy (e.g., regulating water user associations, land titles, property rights, extraction rights, etc.): these laws should build on successful experiences from other countries, but also be founded on a solid understanding of existing arrangements. Finally, the realism of the targets in terms of land titling, an important but complex agenda, could be reviewed. 
25. While substantial progress has been made in education and health service delivery, major constraints persist. Progress includes significant increases in primary enrollment (from 1 million in 2001 to more than 4 million in 2005), increase in functioning health centers, deployment of thousands of community health workers, and massive vaccination campaigns that have reduced polio cases. Looking forward, the most critical issue in health and education will be for the government, as part of the functional review, to clearly outline the service delivery models. Decisions on this issue should be based on empirical analysis such as the experience with the Basic Package of Health Services (BPHS). In particular, government should consider reviewing fiscal affordability, the need for well-trained teachers, an adequate balance between teaching and nonteaching staff and between salary and nonsalary expenditures, and the imperative of clear accountability. Weaknesses in the health strategy include (i) poor focus on family planning and (ii) the need to reformulate or change indicators in a number of programs (i.e., immunization, HIV, malaria).

\section{An appropriate emphasis is placed on enhancing infrastructure, including} transport, power, water, and natural resource management. However, in all these areas, the full ANDS should recognize implementation constraints and the time necessary to build major infrastructure, as well as the consequent delays to realizing benefits. In addition, the recurrent costs of maintaining fixed capital need to be internalized within the national budget framework, with appropriate attention to adequate cost recovery. The strategic benchmarks for national roads and transport are on track. However, continuing focus on provincial and rural access roads, developed on a sustainable basis, will be vital to support greater market integration. Moreover, the issue of long-term maintenance of road structures deserves greater attention. In the telecommunications sector, beyond initial remarkable progress in developing the cell phone market and government communication networks, government needs to renew and implement its commitment to establishing policy and regulatory processes that are transparent and subject to public consultation. In the area of energy and power, adopting cost-effective institutional arrangements and developing government capacity to oversee the swift implementation of the investment program is urgently needed. In addition, a systematic review of cost recovery options and mechanisms in support of a sustainable national energy program is vital. The mineral and hydrocarbon sectors require substantial new private sector participation and an environment that attracts and retains qualified local and international investors. This calls for strengthening public institutions in order to administer the laws and regulations in a transparent manner, and good governance to avoid corruption and misallocation of national resources.

\section{The I-ANDS approach to private-sector led development, notably by} maintaining an open trade regime and strengthening the investment climate, is appropriate. However, while constraints facing the private sector are well identified, the full ANDS should include concrete plans to address bottlenecks, which are related to institutions (reform of state-owned banks and other enterprises, enforcement capacity, and justice system), the regulatory framework, the availability of skilled human resources, and infrastructure. 
28. Effective mainstreaming of gender in the ANDS will continue to be a major challenge, as will be the mainstreaming of other cross-cutting issues. In the area of gender equity, it is vital to move beyond broad strategic objectives toward setting coherent and prioritized actions that can be implemented by various departments. An important strategy would be to strengthen women's roles in areas such as education, health, and the civil service, so as to gain political acceptance before tackling more contentious areas. Outside of the public sector, investments that strengthen the role of women as producers in the rural economy (e.g., micro-finance and the NSP) are a priority. However, some I-ANDS targets (e.g., increasing by 50 percent the number of female teachers) could be reviewed in light of implementation capacity constraints. Other cross-cutting issues (anti-corruption, environment, regional cooperation, and counternarcotics) also require a careful review to ensure realism, mainstreaming, and achievement of desired outcomes.

\section{F. ANDS Timeline}

29. The government needs a realistic timeline to complete the ANDS. The proposed 18-month period could prove difficult in view of: (i) the need for a comprehensive and broad participatory process, with sectoral and thematic consultations throughout the country; (ii) the need to fill significant data gaps and deepen analysis; and (iii) unanticipated delays. We encourage the authorities to target a more reasonable deadline to complete the ANDS.

\section{Conclusion}

30. On balance, the I-ANDS provides an initial comprehensive framework for Afghanistan to build institutions, sustain growth, and reduce poverty. It also lays a solid foundation for developing the full ANDS/PRSP, a process that should allow time for adequate capacity development (notably of monitoring mechanisms) and meaningful participation to enhance the quality and ownership of the national strategy. At the same time, there are considerable risks hindering efforts to meet the targets and important challenges to be addressed while initiating the implementation of the I-ANDS and completing the ANDS.

31. First, there are important macroeconomic, political, and security risks that need to be appropriately identified and managed: (i) maintaining macroeconomic stability in the face of security and political uncertainties, frequent droughts, large inflows of foreign exchange, and limited macroeconomic instruments; (ii) enhancing security and stability in the provinces as well as overcoming political uncertainties; and (iii) reducing the size of, and over time eliminating, the drug economy by developing alternative sources of income.

\section{Second, we recommend that initial implementation of the I-ANDS and} preparation of the ANDS should address the following four main challenges:

(i) Setting priorities and ensuring fiscal sustainability: the policies and measures underlying the government's strategy need to be costed and prioritized to reconcile them with the imperatives of fiscal affordability and capacity constraints. Without this, there is a risk that benchmarks will remain little more than unfunded goals, as they have been in the past. 
This challenge also underscores the need to strengthen budget processes and incorporate the strategy within those processes. Options for cost recovery in key sectors, such as power and water, as well as effective revenue enhancement measures to attain the ambitious revenue targets, are also critical.

\section{(ii) Reforming public administration, tightening public finance management, and}

combating corruption: an effective, streamlined, transparent, and accountable administration is central to state-building, political stabilization, and service delivery. It is also essential in maintaining support from donors and shifting assistance toward the Core Budget. Defining the core functions of government and establishing an effective and accountable public administration both within and outside of Kabul will be a test of government's commitment to implementing the I-ANDS, and will require concerted efforts with civil society and donors. In reviewing the various service delivery functions of government and implementation partners, proposed reforms should be consistent with the human and financial constraints faced by the government. Strengthening budget processes, enhancing fiduciary management, transparency, and accountability should be central tenets of the proposed strategy.

(iii) Developing monitoring mechanisms and the ANDS analytical base: The ANDS should develop a framework for monitoring and evaluation, indicating planned targets against which progress will be assessed for key policies and programs. Equally important will be to initiate the plans for building databases to measure MDG outcomes.

(iv) Strengthening aid effectiveness: strengthening aid effectiveness, in line with the targets set by the Paris Declaration, is key to the success of the national strategy. To garner donor support for this agenda, government needs to make progress during the interim period in the areas of public financial management, fiduciary standards, public administration reform, capacity development, and monitoring. Active coordination is needed to ensure that the transition to donor funding of the Core Budget meshes with the government's reform efforts and budget processes.

\section{Do Executive Directors concur with the broad direction of the proposed}

strategy? In particular: (i) is the macroeconomic framework, financing, and balanced approach to public policy adequately designed to create the necessary conditions to generate growth, improve social sector outcomes, reduce drug-related activities, protect the vulnerable, and improve governance; (ii) are the sectoral priorities linked to strategic goals; (iii) does this note identify the key macroeconomic and implementation risks; and (iv) are the main challenges identified by the JSAN appropriate for the initial implementation of the I-ANDS and the preparation of the ANDS? 